\title{
Naturaleza tridimensional de la "persona jurídica»
}

\section{Carlos Fernández Sessarego}

\section{Complejidad histórica del concepto de "persona jurídica"}

La noción de "persona jurídica» es una de las más complejas de la disciplina jurídica. En cuanto elaboración conceptual de los tiempos modernos, su formulación pandectística resulta ser, de suyo, abstracta $\mathrm{y}$, por consiguiente, difícil de aprehender, sobre todo para los iniciados. Esta particular situación ha generado diversos y encontrados planteamientos teóricos. Una de las aspiraciones más sentidas del derecho contemporáneo, para nosotros aún no logrado, es el de explicar de manera satisfactoria su naturaleza jurídica. Ello, sobre todo, porque la visión del Derecho que se tenía en la no muy lejana época del florecimiento de la pandectística germana no es la que tiende a cobrar vigencia en el umbral de un nuevo milenio. ${ }^{1}$

Durante la vigencia de la escuela pandectística germana, cuya huella aún la percibimos, la concepción formalista-normativista del derecho era pacíficamente aceptada por los juristas. Ella constituía, bien lo sabemos, la visión dominante de lo jurídico. El Derecho era para sus adherentes una impecable construcción exquisitamente conceptual, a la manera de un castillo poblado sólo por normas jurídicas. En él no aparecían ni los seres humanos ni los valores que otorgan sentido y

1 Se considera que el primer autor que trató esta temática fue Sinibaldo dei Fieschi (Inocencio IV). Francesco Ruffini lo presenta como el primer autor que configura la teoría de la ficción ("La classificazione delle persone giuridiche», Milano, Giuffrè, 1936). Gierke expresa que la teoría de la persona jurídica aparece en Sinibaldo dei Fieschi «en un estado de imprevista perfección que despierta maravilla $[\ldots] »$. 
razón de ser a su existencia. Ellos representaban lo metajurídico, lo que está «más allá» del derecho.

Dicha situación cobra vigor con la aparición en el escenario del mundo jurídico de la extraordinaria Teoría Pura del Derecho que, concebida por Hans Kelsen, concitó la atención de los juristas del siglo $\mathrm{XX}$. Sus planteamientos formalistas fueron receptados con entusiasmo, sin problemas ni cuestionamientos, por la inmensa mayoría de los hombres de derecho. Por ello, discrepar de Kelsen era considerado, hasta no hace mucho tiempo, casi como un acto herético. El indudable rigor de la construcción kelseniana así lo justificaba. De ello tenemos personal experiencia. ${ }^{2}$

Si rastreamos en la historia los antecedentes y el decurso del concepto de "persona jurídica", que nace al conjuro de la pandectística germana y que encuentra en Savigny a su más connotado vocero, comprobamos que es en mérito a la construcción expuesta en precedencia que aparece, en tiempos recientes, la inquietud de un sector de jusfilósofos y juristas por revisar, repensar, el originario planteamiento estrictamente formalista de la institución que, convencionalmente, denominamos «persona jurídica». El intento por despejar el interrogante sobre la naturaleza o estructura de la "persona jurídica" ha originado la formulación de una diáspora de contradictorias teorías. ${ }^{3}$ De ahí que el tema sea, con razón, uno de los más debatidos dentro de la jusfilosofía y la dogmática jurídica.

La ciencia jurídica nos muestra una variedad de posiciones adoptadas sobre la estructura de la "persona jurídica». Encontramos desde

2 Siendo estudiantes del primer año de Derecho en la Universidad Nacional Mayor de San Marcos de Lima, luego de haber estudiado Filosofía en la facultad correspondiente de la misma universidad, cuestionamos la conclusión de la Teoría Pura del Derecho en la medida que reducía lo jurídico a la simple formalidad de la norma. Fue así que en nuestra tesis para optar el grado de Bachiller en Derecho, titulada Bosquejo para una determinación ontológica del derecho, presentada en 1950 pero elaborada dentro de los tres o cuatro años anteriores, recusamos no el espléndido desarrollo de la obra kelseniana sino, como está dicho, su conclusión. En dicha tesis concebimos al derecho como un concepto resultante de la interacción dinámica de vida humana social, valores y normas jurídicas.

3 Debemos testimoniar que como estudiantes de Derecho no logramos, pese al empeño de nuestros profesores, comprender cuál era la naturaleza de la persona jurídica. Nos resistíamos a admitir, pese al magister dixit, que la persona jurídica fuera un concepto, una abstracción, cuando el derecho era, según también se nos enseñaba, una ciencia social, instalada en la vida. Y, en la realidad de la vida, no hallábamos a la "persona jurídica" por cuanto era, como está dicho, un concepto inasible. Un concepto sin correspondencia en la realidad. 
aquellas precursoras de Savigny o Gierke, que marcaron época, hasta la de los juristas que recientemente se han ocupado con solvencia del tema como es el caso, entre otros, de Federico de Castro y Bravo, ${ }^{4}$ Francesco Galgano, 5 . Riccardo Orestano ${ }^{6}$ o de jusfilósofos como Kelsen, ${ }^{7}$ Hart, ${ }^{8}$ Ross ${ }^{9}$ o Scarpelli. ${ }^{10}$

El debate en torno a la naturaleza de la institución del Derecho denominada "persona jurídica» se mueve, fundamentalmente, entre dos polos. En el primero se sitúan los que consideran que ella es sólo un artificio, una ficción, como es el caso del ya citado Savigny. En el otro extremo se ubican, con diferentes matices, los que estiman que los grupos humanos jurídicamente actuantes no podían desvanecerse totalmente en una ficción. En esta posición encontramos a Gierke. Para el derecho la vida no es evanescente, no se evapora en puros conceptos.

En el rico muestrario de opiniones encontramos una matizada gama de soluciones formalistas, como la que nos ofrecen, entre otros, Kelsen y Hart, o la de pensadores que, como Galgano, sostienen que la naturaleza de la "persona jurídica" se contrae a la de ser una simple expresión linguística. Este autor considera que ella pertenece a lo que designa como «la escena conceptual verbalizada», desde que a estas específicas palabras no corresponde ningún ente real. La "persona jurídica» es un centro autónomo de imputación de relaciones jurídicas, es decir, una expresión resumida de una especial disciplina normativa. ${ }^{11} \mathrm{Y}$ es que para Galgano, al igual que lo que sostuvieran Savigny o Cossio en su momento, en el mundo existencial no aparece otro sujeto de derecho que no sea el ser humano individualmente considerado.

\footnotetext{
4 Federico De Castro y Bravo, La persona jurídica, Madrid, Civitas, 2a. edición, 1984.

5 Francesco Galgano, Persone giuridiche, Bologna, 1969 y «Struttura logica e contenuto normativo del concetto di persona giuridican, en : Rivista di Diritto Civile, 1965, 1, p. 553 y ss.

6 Riccardo Orestano, Il problema delle persone giuridiche in diritto romano, Torino, Giapichelli, 1968.

7 Hans Kelsen, La Teoría Pura del Derecho, Buenos Aires, Losada, 1946.

8 Hart, H.L.A., El concepto de derecho, Buenos Aires, Abeledo-Perrot, traducción de Genaro Carrió, 1963 y Contributo all"analisi del diritto, Milano, 1964.

9 Alf Ross, Diritto e giustizia, Torino, 1965.

10 Uberto Scarpelli, Contributo alla semantica del linguaggio normativo, Torino, 1959.
} 


\section{La concepción formalista de Hans Kelsen}

Cabe mencionar, dentro de las múltiples respuestas de carácter formalista que se han formulado sobre la "persona jurídica", aquella elaborada por Hans Kelsen. Este pensador es, sin duda, el gran artífice del constructivismo conceptual al reducir el Derecho a una mera forma, con exclusión de la vida humana y los valores. La "Teoría Pura del Derecho", por su valor intrínseco, tuvo amplia resonancia universal y una irresistible atracción. Kelsen, como es sabido, depura la teoría formalista sobre la persona llevándola, con lúcida coherencia, a sus últimas consecuencias.

Dentro de su concepción, como no podía ser de otra manera, la persona, tanto la natural como la jurídica, resultan ser un puro concepto desarraigado de la realidad de la vida. La persona es así, tan sólo, un centro ideal de imputación, un modo especial de designar unitariamente una pluralidad de normas que atribuyen derechos y deberes o, como decimos actualmente, "situaciones jurídicas subjetivas». ${ }^{12} \mathrm{~A}$ esta conclusión se llega luego de la eliminación del derecho subjetivo, el mismo que Kelsen asimila al derecho objetivo en cuanto sostiene que no son de diferente naturaleza. Así, a través de la concepción kelseniana se ha consumado la identificación del concepto de Derecho con el de derecho objetivo, es decir, con el ordenamiento jurídico positivo. La vida humana y los valores son, dentro del planteamiento kelseniano, nociones transistemáticas, entes metajurídicos situados allende el derecho.

\section{El pensamiento contemporáneo y la "persona jurídica»}

Las posiciones radicalmente formalistas, como la que postula Kelsen en su afán por descifrar la naturaleza de la "persona jurídica», fueron consideradas insatisfactorias por un sector de la doctrina. Ellas originan, dentro del pensamiento contemporáneo, encontradas reacciones. Frosini, con acierto, sintetiza esta situación al expresar que el formalismo persigue reducir al Derecho, y por tanto a la "persona jurídica», a

11 Francesco Galgano, cfr. las obras señaladas en la nota 4.

12 Hans Kelsen, La Teoría Pura del Derecho, p. 83. 
un mero "castillo habitado por fantasmas». ${ }^{13}$ Orestano, por su parte, rechaza, toda solución espectral y esquemática, propia de la dogmática tradicional, que pretende vanamente sustituir la experiencia jurídica, donde realmente se vive el Derecho, por una mera formalidad. El autor reivindica, con convicción, el rol protagónico que corresponde al ser humano en el mundo jurídico. ${ }^{14}$

Rescigno designa como «sujetos de la actividad jurídica» tanto a las personas naturales como a las jurídicas y a los entes que denomina «de hecho" y que, para nosotros, son «organizaciones de personas no inscritas" ${ }^{15}$ reguladas por el Código Civil peruano de 1984. La expresión escogida por Rescigno es, según su criterio, más amplia que la de «sujeto de derecho" ya que con ella cabe referirse a todos los entes actuantes. En cuanto a la "persona jurídica" distingue un elemento material, que es el substrato, de otro elemento formal. El primero está compuesto por la «organización de personas» en vista a una determinada finalidad, actuante en la realidad de la vida, mientras que el formal está constituido por la creación de un centro unitario de referencias normativas. Rescigno, al no apartarse de la realidad, reconoce la presencia, como no podía ser de otra manera, de los seres humanos dentro de la estructura de la persona jurídica.

Se advierte, a través del pensamiento de los autores antes citados, la insuficiencia de una respuesta únicamente de carácter formal para una aprehensión global de la naturaleza compleja de la "persona jurídica" en la medida que, detrás del marco estrictamente lógico-formal a la que la redujo la posición formalista, se mueven y actúan seres humanos que vivencian valores. Tal vez, la primera elíptica reacción ante esta evidencia fue, aun bajo la gravitación del pensamiento formalista, la de imaginar metáforas para aproximarse a esta realidad. Nos referimos, principalmente, a aquella que para superar la pura "forma" en que, cerrada y rígidamente, yacía la palpitante realidad de la "persona jurídica», alude al hecho de "descorrer el velo" que la cubre para poder llegar a su realidad existencial. Así, a través de elusivas metáforas, los

13 Vittorio Frosini, "Il soggetto del diritto come situazione giuridica", en Rivista di Diritto Civile, No 1, 1969, p. 227 y ss. y La estructura del derecho, Bologna, 1974.

14 Riccardo Orestano, Il problema delle persone giuridiche in diritto romano, Torino, Giapichelli, 1968 y Azione, diritti soggettivi, persone giuridiche, Bologna, Il Mulino, 1978.

15 Esta es la denominación que encontramos en el Código Civil peruano de 1984. 
juristas empiezan a intuir que el elemento primario del Derecho es la vida humana con los valores que ella vivencia y realiza. Podemos aseverar, luego de estas expresiones, que la noción de "persona jurídica» ha entrado en crisis. ${ }^{16}$

Es así que, a partir del «redescubrimiento» de la vida humana por los filósofos de la primera mitad del siglo XX, el pensamiento contemporáneo en torno a la naturaleza de la "persona jurídica" comienza a discurrir en una dirección tendente a superar la respuesta exclusivamente formalista, sin que ello signifique negar o ignorar la indispensable función que, dentro de la noción unitaria de la misma, le cabe a su dimensión lógico-formal.

\section{El proceso de revalorización de la vida humana}

Para precisar la naturaleza de la "persona jurídica", más allá de las estrechas lindes en las que la encerró la dogmática jurídica tradicional, se hace necesario recurrir a la antropología filosófica en tanto que una mejor comprensión de lo que significa el ser humano es la única vía para entender, a cabalidad, aquello en que consiste la institucionalidad jurídica. No se puede descifrar lo que significa el Derecho sin aproximarse a la realidad en que consiste la vida humana. No podemos olvidar que el Derecho ha sido creado "por" y "para" el hombre, para su pacífica convivencia, a fin de lograr que cada uno, en cuanto ser libre, pueda realizarse como persona dentro del bien común. ¿Cómo proteger jurídicamente lo que se desconoce? ¿Cómo tutelar al ser humano desconociendo su naturaleza?.

El proceso de revalorización del ser humano, como eje y centro del discurrir jurídico, se produce como resultado de los extraordinarios aportes provenientes del fecundo pensamiento de la filosofía existencial en la escena contemporánea. Jaspers, Heidegger, Zubiri, Sartre, Marcel, antes Kierkegaard y más tarde Mounier, «redescubren» al ser humano que había sido caracterizado por el cristianismo como un ser libre, que podía salvarse o perderse. El aporte del cristianismo sobre la naturaleza de la persona humana se fue oscureciendo a través de la historia para dar paso a un puro "racionalismo" a la manera de Boecio.

16 Rolf Serick, Forma e realtà della persona giuridica, Giuffrê, Milano, 1996, p. 6. 
En pleno siglo XX, que al decir de Miró Quesada es el siglo más filosófico de la historia, se logra ampliar y enriquecer la antigua prevaleciente concepción, reafirmada por Boecio en el siglo VI, por la que se describía al ser humano como "una sustancia indivisa de naturaleza racional». En efecto, frente a esta clásica definición, que ha atravesado los siglos y ha reposado en numersos textos, los hallazgos a que arribó la filosofía de la existencia nos muestran que el ser humano, como lo había puesto de manifiesto el cristianismo, es más que una pura "racionalidad». Ello, por cuanto es un «ser libertad», temporal, creativo, lábil, singular, que vivencia valores al efecto de proyectar su vida. Cada ser humano es único e irrepetible, idéntico a sí mismo. La dignidad, que le es inherente, se fundamenta, precisamente, en su propia naturaleza de ser libre. Su libertad lo hace único, singular.

$\mathrm{Al}$ afirmarse la libertad del ser humano se nos muestra también que este ser único e irrepetible, idéntico a sí mismo, tiene simultáneamente una dimensión coexistencial, lo que significa que para "hacer su vida" requiere de los «otros» seres humanos. Es decir que, sin dejar de ser idéntico a sí mismo es, al mismo tiempo, un ente coexistencial. Lo social, por ende, participa de su propia estructura, de donde se puede sostener que la existencia es coexistencia.

La coexistencialidad en que consiste el ser humano hace que el Derecho sea una necesidad existencial. Las normas jurídicas, en cuanto estructura lógico-formal de lo jurídico, están destinadas a regular valiosamente la coexistencialidad, a fin de que cada ser humano pueda vivir su vida de libertad dentro del bien común. Descubrir y poner en evidencia la libertad y la coexistencialidad inherentes a la naturaleza del ser humano permite explicar al Derecho como una dinámica interacción de conductas humanas intersubjetivas, valores y normas jurídicas. No hay Derecho sin vida humana social que requiera, para su convivencia, de normas jurídicas que la regulen de acuerdo a valores. Se trata de realizar comunitariamente la justicia, la solidaridad, la seguridad, entre otros valores, para crear un ambiente propicio para el mejor desarrollo integral de la persona.

El Derecho, como concepto unitario, no puede prescindir ni de la vida humana social, ni de los valores ni de las normas jurídicas. Sin vida humana el Derecho no tendría razón de ser, no existiría. Sin normas jurídicas no cumpliría su función existencial. Sin valores, se carecería de criterios para regular las conductas humanas intersubjetivas. Ninguno de estos tres objetos constituye, por sí mismo, el Derecho, 
aunque, al mismo tiempo, es imposible dejar de lado alguno de ellos si se pretende aprehender "lo jurídico" como un concepto unitario. Es decir, se requiere de una concepción tridimensional del Derecho para captarlo a plenitud, como una totalidad. En cualquier institución jurídica se hayan presentes los seres humanos que exigen que sus conductas intersubjetivas sean reguladas valiosamente a fin de poder convivir en cuanto seres libres y coexistenciales.

A partir de la concepción tridimensional del Derecho, que se sustenta en el personalismo, se advierte el esfuerzo de un sector de juristas por rescatar el rol protagónico del ser humano en el Derecho. Ello contribuye, como anota Zatti, a sustraer una serie de problemas de la "persona jurídica» a la simple y frustrante "esclavitud de la forma y al mecánico respeto a la distinción entre ente e individuon. ${ }^{17}$ Es decir, a aquella distinción entre el plano lógico-formal de las abstracciones ideales y la realidad de la vida humana, de la experiencia jurídica.

La revalorización del ser humano en cuanto tal -que por lo demás tiene un revelador antecedente en la histórica intuición de Hermogeniano-, el redescubrimiento del rol protagónico y central que él ocupa en el Derecho y la concepción tridimensional, constituyen la sólida base que permite elaborar una nueva concepción en cuanto a la naturaleza de la "persona jurídica».

La aplicación de la teoría tridimensional del Derecho, ${ }^{18}$ por su parte, nos conduce a distinguir en cualquier institución jurídica $y$, por consiguiente en la "persona jurídica», la presencia simultánea y en recíproca exigencia, de tres objetos heterogéneos que adquieren unidad conceptual mediante una interacción dinámica. Nos referimos, como está dicho, a las conductas humanas intersubjetivas, los valores y las normas jurídicas. No puede perderse de vista que, como lo señalara Cossio en la década de los años cuarenta, el ser humano es el único ente que vivencia valores y que produce normas, ya sea a través de costumbres inveteradas o de abstracciones conceptuales.$^{19}$

17 Paolo Zatti, Persona giuridica e soggettività, Pasdova, Cedam, 1975, p. 6.

18 Sobre la teoría tridimensional del derecho cfr. Carlos Fernández Sessarego, El derecho como libertad, Lima, Universidad de Lima, 1987 y Derecho y persona, tercera edición, Lima, Grigley, 1998, así como Miguel Reale, Teoría Tridimensional del Derecho, Valparaíso, Edeval, 1978.

19 Carlos Cossio, La teoría egológica del derecho y el concepto jurídico de libertad, segunda edición, Buenos Aires, Abeledo-Perrot, 1963. 


\section{Dimensión formal de la "persona jurídica»}

Desde un punto de vista estrictamente formal, la "persona jurídica», tal como se ha evidenciado, se constituye en un centro unitario ideal de referencia de situaciones jurídicas subjetivas, es decir, de derechos y deberes. Desde esta perspectiva, ella se reduce a un simple dato formal al cual se llega después de un proceso de abstracción mediante el que se logra reducir a la unidad ideal una pluralidad de personas, las que subsisten en la experiencia jurídica y que, a través de una organizada actividad en común, se proponen alcanzar determinados fines valiosos.

El proceso de abstracción mental en referencia queda consumado, como por arte de magia, en el instante en el cual, según lo dispongan los respectivos ordenamientos jurídicos positivos, se produce, según sea el caso, la inscripción en un determinado registro público o cuando se obtiene el reconocimiento gubernativo, o cuando se cumplen ambos requisitos. Es en este instante en el cual, por consenso que se sustenta en una prescripción normativa, admitimos que ha surgido un centro unitario ideal de referencia de derechos y deberes, es decir, de situaciones jurídicas subjetivas. En otros términos, un sujeto de derecho ideal que no encuentra correspondencia en la realidad.

Pero, como se ha anotado en precedencia, en el momento en que se produce la reducción formal a la unidad y la "persona jurídica" queda sujeta a un cierto régimen normativo de excepción, no desaparecen de la realidad, tampoco por arte de magia, ni el conjunto de personas humanas que la integran ni los fines valiosos por ellas perseguidos. Por el contrario, ellas siguen actuando organizadamente, vivenciando y realizando comunitariamente los fines valiosos que determinaron su constitución. Para apreciarlo no es necesario «descorrer» ningún «velo» sino observar lo que, real y efectivamente, sucede en la experiencia jurídica.

A pesar de que la estructura formal constituye el sujeto de derecho denominado "persona jurídica», en cuanto centro de imputación ideal y unitario de referencias normativas, no son extraños a su naturaleza las otras dos estructuras que la conforman, como son la organización de personas $^{20}$, que le sirve de soporte en la realidad y que es la fuente

20 Aludimos a la "organización de persona» en tanto que los seres humanos que constituyen una persona jurídica no se reúnen sin fines ni concierto. Por el contra:io, ellos se 
generadora de derechos y deberes a ser imputados al centro ideal, así tampoco ello ocurre tratándose de los valores jurídicos vivenciados por los miembros que la integran. La estructura existencial y la axiológica, si bien no fungen como centro de imputación de referencias normativas como sí lo sería la organización de personas no inscrita- no son ajenos a la naturaleza misma de la persona jurídica pues sin ellas dejaría de ser lo que es. Ni la vida humana social, ni los valores, son metajurídicos en el caso de la persona jurídica como en el de ninguna otra institución jurídica. Sin vida humana y sin valores no se concibe el Derecho.

La persona jurídica no se reduce ni se confunde, única y exclusivamente, con su dimensión formal-normativa no obstante que ella es determinante para su constitución como sujeto de derecho, es decir, como centro de imputación de situaciones jurídicas subjetivas. Ello, de ocurrir, supondría el absurdo de prescindir de los seres humanos que la crearon, que actúan en la experiencia jurídica y que concretan en actos jurídicos los fines valiosos que se propusieron al constituirla. La «magia», o el «invento», funciona sólo con el exclusivo propósito de proceder a su reducción a una unidad ideal que, como está dicho, funciona como un centro de referencia de situaciones jurídicas subjetivas. Pero, lo reiteramos, en ningún caso para que desaparezcan, ni el conglomerado de seres humanos que organizadamente la integran, ni los fines valiosos que proyectaron realizar sus fundadores.

La unilateral pretensión de reducir la naturaleza de la "persona jurídica" únicamente a la unidad formal nos impide comprenderla en su totalidad existencial, tal como opera en la realidad. La concepción exclusivamente formalista nos proporciona tan sólo una visión parcial o fragmentaria de la misma. Es en la experiencia jurídica donde debemos aprehenderla para luego describirla. Y, si seguimos este periplo, que es válido para el caso de cualquier institución jurídica, no podremos reducirla, en cuanto a su naturaleza, sólo y exclusivamente a un dato formal, a un centro unitario ideal de imputación de situaciones jurídicas subjetivas. Como surge de la directa e inmediata observación de la realidad, la "persona jurídica" no se confunde únicamente con su expresión formal, aunque es ella la determinante para considerarla como sujeto de derecho Su exclusiva captación resulta del todo insuficiente

proponen fines valiosos a realizar durante su vigencia y se distribuyen las tareas que asumirá cada uno o colectivamente para el logro de aquellos fines. 
para comprender qué es la "persona jurídica» y el sentido que ella tiene para la vida humana.

El centro unitario ideal de imputación de situaciones jurídicas subjetivas, en cuanto dimensión formal de la "persona jurídica", cumple tan sólo la importante función de facilitar el que las situaciones jurídicas subjetivas que se crean en la vida asociativa no se imputen, en forma directa e inmediata a todos y a cada uno de los seres humanos que la integran a la manera de las tradicionales collegia, universitas personarum o de las actuales organizaciones de personas no inscritas, sino que se atribuyan a un centro ideal y unitario de referencias normativas. El invento de la persona jurídica, en cuanto dato formal que funge como sujeto de derecho, permite aligerar extraordinariamente las relaciones humanas y los negocios jurídicos, al imputar a dicho centro ideal los derechos y deberes que generan sus miembros. Es así, bien lo sabemos, que una persona, gracias a este invento de la pandectística puede representar a una pléyade de integrantes de la persona jurídica, evitando de este modo que todos ellos intervengan en cada acto jurídico practicado por la organización.

Además, y esto no es menos importante, el invento de la persona jurídica, como abstracción conceptual ideal y unitaria de una pluralidad de personas, permite también el evitar que, normalmente, cada uno de sus miembros no sea responsable de las obligaciones por ella contraídas. De este modo, el participar en alguna actividad asociativa de carácter lucrativo no compromete el patrimonio de una persona, sino tan sólo aquella parte del mismo que aporta a la persona jurídica de la que es miembro.

En nuestro concepto, al partir siempre de la realidad de la vida que es la del Derecho, el invento de la "persona jurídica" no es, como pretendía Savigny, un mero "artificio". Un artificio al que, acudiendo a una ficción, se le concedía la calidad de sujeto de derecho, categoría jurídica que sólo corresponde al ser humano, individual o colectivamente considerado. El Derecho, como en la actualidad lo comprende un sector cada vez más numeroso de juristas es, primariamente, vida humana, relación entre seres humanos valiosamente regulada. Ellos no pueden ser olvidados mediante una ficción cuando se trata de explicar o describir la naturaleza de la persona jurídica. No podemos exiliarlos del Derecho, así como tampoco podemos dejar de considerar los valores que orientan su existencia. 
Tal vez lo que ha originado el desconcierto, que aún persiste, sobre la naturaleza de la "persona jurídica" radique en el hecho de que, para Savigny, sólo es persona el ser humano individualmente considerado. $\mathrm{Al}$ no comprender que el ser humano es, simultáneamente, un ente estructuralmente coexistencial, la posibilidad de que pudiera también existir, al igual que la persona individual, una persona colectiva. Es decir, un sujeto de derecho que agrupe a una pluralidad de seres humanos que, a través de una actividad común, se proponen alcanzar determinados fines valiosos. Tal sujeto de derecho es el ser humano individualmente concebido como aquél que comprende a una pluralidad de personas. El hecho de la inscripción en un determinado registro de parte de esta pluralidad de personas no las hace desaparecer de la escena jurídica.

\section{Descripción del fenómeno conocido como "persona jurídica»}

En principio, como se ha advertido y fluye de la realidad de la vida, la "persona jurídica» requiere primariamente, como cualquier otra institución del Derecho, de un sustrato humano. Es decir, de una relación interpersonal. Dicho sustrato humano está compuesto por las personas que, al ejercer su derecho a la libre asociación, constituyen e integran la persona jurídica ${ }^{21}$. Sin la presencia actuante de estos seres humanos es imposible imaginarla o concebirla. La persona jurídica aparece en el escenario del Derecho debido a la iniciativa y a la decisión de seres humanos. Son los seres humanos los que fijan las finalidades valiosas por alcanzar y se organizan en función de estos fines. Son estas personas naturales las que, en la realidad de la vida, celebran los actos jurídicos que no los comprometen sino que sus efectos, en razón de un mandato legal y la consiguiente inscripción en un registro, se derivan a un centro ideal unitario de referencias normativas por ellos creado. Son estos seres humanos los que constituyen la ineludible e insoslayable dimensión sociológico-existencial de la "persona jurídica".

21 El inciso 12 del artículo $2^{\circ}$ de la Constitución peruana de 1993 reconoce el derecho de la persona: " $A$ asociarse y a constituir fundaciones y diversas formas de organización jurídica sin fines de lucro, sin autorización previa y con arreglo a ley. No pueden ser disueltas por resolución administrativa". 
El grupo humano, que constituye la dimensión primaria de la «persona jurídica», actúa organizadamente para lograr un fin o un conjunto de fines valiosos. Es este fin valioso, vivenciado por cada uno de sus componentes, el que aglutina a la comunidad de personas y otorga un sentido a su específica actividad. Percibimos así la dimensión axiológica de la "persona jurídica». Dimensión que, al igual que la sociológicoexistencial, es también ineludible e insoslayable tratándose de la persona jurídica.

La "persona jurídica", en cuanto organización de personas que persigue fines valiosos, requiere que, mediante un recurso propio de la técnica jurídica, se le considere, pese a su pluralidad existencial, como una unidad formal para el efecto de lograr que los actos jurídicos que realizan sus miembros no se les impute a todos ni a cada uno de ellos, en forma inmediata y directa, sino que se atribuyan a un centro ideal de referencia de situaciones jurídicas subjetivas. La "persona jurídica" tiene una especial regulación normativa. Esta constituye su dimensión formal-normativa, cuya nota distintiva es su excepcionalidad en relación con el derecho común que regula a las organizaciones de personas que, por no inscribirse en un registro especial, no gozan del privilegio propio de un régimen de excepción que la ley otorga a las personas jurídicas.

\section{Visión tridimensional de la persona jurídica}

La "persona jurídica» es el resultado de la interacción dinámica de sus dimensiones sociológico-existencial, axiológica y formal-normativo a las que nos hemos referido en precedencia. Para comprenderla unitariamente no es posible prescindir de alguna de ellas ya que, de hacerlo, tendríamos tan sólo una visión recortada, parcial y fragmentaria de la misma. En la persona jurídica, los seres humanos, a través de sus conductas intersubjetivas, interaccionan con los valores que vivencian y que otorgan un sentido a su accionar $y$, ambos, con la normatividad jurídica que regula tales conductas, especialmente con aquella norma de excepción que permite derivar sus derechos y deberes a un centro ideal y unitario de referencias normativas.

El Código Civil peruano de 1984 ha recogido la visión tridimensional de la "persona jurídica». Ello se pone de manifiesto a través del texto de los artículos $80^{\circ}, 99^{\circ}, 111^{\circ}$ y $134^{\circ}$, en los que se describe a la asocia- 
ción, a la fundación, al comité y a la comunidad campesina y nativa, respectivamente. En todos aquellos numerales se hace referencia a que cada una de dichas "personas jurídicas" es una "organización de personas" que se propone fines valiosos de carácter no lucrativo. Es decir, en los citados artículos se mencionan tanto la dimensión sociológicoexistencial como la dimensión axiológica de la persona jurídica.

En el Art. $78^{\circ}$ se hace alusión al dato más importante de la dimensión formal-normativa cuando se establece que la "persona jurídica" tiene existencia distinta de sus miembros, por lo que ninguno de éstos, ni todos ellos, tienen derecho al patrimonio de ella ni están obligados a satisfacer sus obligaciones. En concordancia con lo dispuesto en el articulado citado en el párrafo anterior, debe entenderse que dicha distinción es tan sólo formal y, en cuanto se trata de un recurso de técnica jurídica, opera exclusivamente para la atribución de situaciones jurídicas subjetivas a un centro ideal de referencia formalmente «distinton de sus miembros.

No obstante que debería entenderse que la «distinción» entre los miembros de la persona jurídica y el centro de referencias normativas es tan sólo formal, desde que no puede prescindirse de los seres humanos y de los valores por ellos realizados, la común y general interpretación del artículo $78^{\circ}$ del Código Civil peruano considera que la naturaleza de la persona jurídica, en tanto sujeto de derecho, deja de lado a los seres humanos que la integran y a los valores que persiguen.

El que la persona jurídica se constituya como un sujeto de derecho, en tanto que es al centro unitario e ideal al que se atribuyen los derechos y deberes que normalmente corresponderían a todos y cada uno de sus miembros, ello no significa prescindir de los seres humanos que la integran y los fines valiosos que se persigue cuando se hace mención a su naturaleza como institución jurídica. Si bien los seres humanos y los valores no son directamente el sujeto de derecho tratándose de la persona jurídica, ello no significa que no participen de su «naturaleza». No puede concebirse a la persona jurídica como una pura forma, en la que no cuentan ni los seres humanos ni los valores. El recurso formal, como está dicho, es un recurso instrumental por el cual los derechos y deberes contraídos por los miembros que la integran se derivan a un centro ideal de referencias normativas.

Es fácil advertir una contradicción entre lo descrito en los artículos $80^{\circ}, 99^{\circ}, 111^{\circ}$ y $134^{\circ}$ y lo prescrito en el artículo $78^{\circ}$ antes mencio- 
nado. En efecto, al describir aquellos artículos a cada una de las personas jurídicas reguladas en el Código Civil -asociación, fundación, comité y comunidad campesina y nativa- establecen que son «organizaciones de personas que persiguen finalidades valiosas» no lucrativas, mientras que en artículo $78^{\circ}$ se considera a la persona jurídica como «distinta de sus miembros». Insistimos que la distinción existe pero que ella es sólo "formal», es decir, en lo que atañe a la imputación de derechos y deberes, más no en cuanto a la naturaleza misma de la persona jurídica, ya que los seres humanos y los valores por ellos vivenciados son inherentes a su naturaleza.

Como el Derecho es primariamente vida, debemos partir de ella para describir-prescribir lo atinente a la persona jurídica. Es por ello importante otorgar al artículo $78^{\circ}$ del Código civil peruano una redacción en la que se comprendan los alcances de la "distinción" entre el sujeto de derecho -como centro ideal y unitario de imputación de derechos y deberes- y los seres humanos que la componen. Fue así que en el proceso de revisión del actual Código civil propusimos el siguiente texto:

Art. $78^{\circ}$.- Por la inscripción en el registro respectivo, una organización de personas adquiere la calidad de persona jurídica, constituyéndose un centro unitario y formal para la atribución de derechos y deberes, por lo que ninguno de sus miembros ni todos ellos tienen derecho a su patrimonio ni están obligados a satisfacer sus obligaciones.

En el texto en referencia se describe, con la mayor aproximación posible, tanto el proceso de creación de la persona jurídica así como su calidad de sujeto de derecho y sus consiguientes efectos. Se trata, como se advierte, de una "organización de personas" que decide constituirse en persona jurídica para lo cual procede a su inscripción en el registro respectivo. Esta inscripción origina el que los derechos y deberes asumidos no se imputen ni a todos ni a cada uno de los integrantes de la «organización de personas», como ocurriría en el derecho común, sino que se crea un régimen de excepción por el cual tales situaciones jurídicas subjetivas se derivan a un centro ideal y unitario.

Tanto en 1984, cuando se redactó el vigente artículo $78^{\circ}$ como en el actual proceso de revisión del mismo, hemos manifestado nuestro 
desacuerdo con la redacción empleada, pues de ella no se derivan los alcances de la "distinción" entre el sujeto de derecho y sus miembros. Fue así que en la Exposición de Motivos de dicho artículo, redactada en 1985, aludimos a la persona jurídica "como una expresión lingüística que alude a una organización de personas que persigue fines valiosos y que constituye un centro ideal de imputación de situaciones jurídicass. ${ }^{22}$

La persona jurídica, como concepto, no tiene un correlato en la realidad. No hay un objeto real por él mentado. Es como el número cuatro, que no existe en la realidad. Pero, en ambos casos, dichos conceptos se refieren a determinados procesos que sí ocurren en la realidad. En el caso de la persona jurídica encontramos que es la expresión de seres humanos persiguiendo fines valiosos, mientras que el número cuatro es la expresión de cuatro seres humanos, de cuatro objetos cualquiera. Si bien ni la persona jurídica ni el número cuatro son objetos que se hallan en la realidad, en ésta sí encontramos los procesos por los cuales ellos se configuran en la realidad.

En la realidad la persona jurídica supone la existencia actuante de una "organización de personas» que realiza fines valiosos más, en tanto centro unitario e ideal de imputación de situaciones jurídicas subjetivas, es tan sólo una expresión lingüística. El dato formal se diferencia de otro sólo por esta expresión lingüística, ya que todos los datos formales son lo mismo: "centros ideales y unitarios de imputación de situaciones jurídicas subjetivas". ¿Cómo diferenciar formalmente uno de otro si no es a través de su expresión lingüística?

La Comisión que en la actualidad está elaborando diversas enmiendas al Código Civil de 1984, con las reservas de quien esto escribe, aprobó el siguiente texto del artículo $78^{\circ}$ en referencia:

Art. $78^{\circ}$.-

1.- La persona jurídica es sujeto de derecho distinto de sus miembros.

22 Carlos Fernández Sessarego, Derecho de las Personas. Exposición de Motivos y comentarios a Libro Primero del Código civil peruano, Lima, Grigley, sexta edición, 1996, p. 194. 
2.- Ninguno de éstos ni todos ellos tienen derecho al patrimonio de ella ni están obligados a satisfacer sus deudas, salvo disposición legal diferente.

3.- Excepcionalmente, la distinción prevista en el primer párrafo queda desestimada en caso de uso abusivo o fraudulento de la estructura formal de la persona jurídica. En tal supuesto, son responsables los miembros que hayan utilizado tal estructura abusivamente o con fraude a la ley.

En el primer párrafo del citado proyecto se aclara que la persona jurídica, en cuanto sujeto de derecho, es distinto de sus miembros. Es decir, desde un punto de vista formal. Ello no incide, por lo tanto, en la naturaleza misma de la persona jurídica donde interactúan dinámicamente conductas humanas intersubjetivas, valores y normas jurídicas. Entre estas últimas, sobre todo, las que coinciden con el contenido del artículo $78^{\circ}$ del Código Civil peruano.

En el segundo párrafo se indican los efectos de la declaración contenida en el primer párrafo, en el sentido de que los derechos y deberes que deberían recaer en todos y cada uno de los miembros de la «organización de personas", por el hecho de la inscripción en un registro, se derivan, por excepción, a un centro ideal y unitario de referencias normativas que se distingue de los demás por su expresión lingüística.

En el tercer párrafo se regula la tan discutida figura conocida como la del «abuso de la personalidad jurídica». Este párrafo es revelador de que no puede prescindirse del sustrato existencial de la persona jurídica. En él se determina que la distinción prevista en el primer párrafo, entre persona jurídica y sus miembros, queda desestimada en caso de uso abusivo o fraudulento de la "estructura formal" de la persona jurídica. En esta situación, desaparece la distinción, que era puramente formal, para hacer personalmente responsables a los seres humanos que actuaron abusivamente o con fraude a la ley.

El texto de este párrafo pone en evidencia que existe una estructura formal en la institución que denominamos "persona jurídica». Ello significa, tácita o implícitamente, reconocer que, al lado de esta estructura, existen otras como serían la existencial y la axiológica que integran la naturaleza de esta institución. Se hace también patente que la formalidad se desvanece y la distinción se esfuma cuando en la estructura existencial y axiológica se advierten conductas abusivas o fraudulentas. 
Estas conductas intersubjetivas son determinantes para el reconocimiento de la naturaleza compleja de la persona jurídica.

El que se desestime la distinción prevista en el primer párrafo del proyectado artículo $78^{\circ} \mathrm{y}$ del mismo numeral del Código Civil peruano significa que se pone fin al privilegio que, excepcionalmente, el ordenamiento jurídico concede a una "organización de personas" que decide que sus miembros sean irresponsables frente a las obligaciones por aquella contraídas. Privilegio que consiste en derivar derechos y deberes a un centro unitario e ideal de referencias normativas. Se elimina en este caso un régimen de excepción y la "organización de personas" retorna a ser regulada por el derecho común, como siempre había ocurrido antes de la aparición del formidable invento de la persona jurídica como exigencia del mundo moderno.

Así, lentamente, la nueva concepción tridimensional de la persona jurídica se abre paso en la doctrina y en la legislación contemporánea. Visión tridimensional en la cual se privilegia el dato formal, que es el determinante para la derivación de derechos y deberes a un sujeto de derecho fuera de la realidad que opera como centro unitario e ideal de referencias normativas. Concepción en la cual, sin embargo, no se desestima la presencia, en la realidad, de una "organización de personas" que persigue fines valiosos. Estos tres elementos en dinámica interacción constituyen la compleja naturaleza de la persona jurídica. Ninguno de ellos puede faltar pues si así sucediera se desvanecería la institución de la persona jurídica.

La persona jurídica no puede actuar sin la presencia de seres humanos que operan en la realidad o sin valores por ellos realizados, aunque el privilegio de excepción en que ella consiste se determine a través de una norma jurídica. Por ello, la famosa distinción entre la persona jurídica, en cuanto sujeto de derecho, y los miembros que la constituyen no es absoluta ni radical, sino solamente formal. De ahí que tal distinción pueda desestimarse en caso de conductas abusivas o fraudulentas de parte de sus integrantes. Todos aquellos elementos pertenecen a la naturaleza de la persona jurídica, son inherentes a ella. No podemos prescindir de ninguno de ellos si queremos situarnos frente al fenómeno que en el derecho designamos como "persona jurídica". Es decir, si deseamos captarla como una totalidad, sin desvirtuar su naturaleza.

De este modo, gracias a los aportes de la filosofía existencial y del tridimensionalismo, se ha logrado en nuestros días concretar 
normativamente una nueva visión de la "persona jurídica" que, al superar las limitaciones de una concepción del todo formalista y al describirla tal como aparece y funciona en la experiencia jurídica, nos la muestra como una totalidad, por lo que se hace imposible prescindir de alguna de sus tres dimensiones en la medida que interactúan dinámicamente. En mérito a estos hallazgos se abre un capítulo más en el insosegable afán de los hombres de derecho por captar, a plenitud y con nitidez conceptual, aquello en que podría consistir la denominada "persona jurídica". 